\title{
Study of the Emissions from the Fuel Distribution Stations in Drobeta Turnu Severin
}

\author{
Ionela Bucse ${ }^{1, a}$, Olimpia Ghermec ${ }^{1, b}$, Elena Gavrilescu ${ }^{2, c}$, \\ and Mariana Ciobanu ${ }^{1, d}$ \\ ${ }^{1}$ University of Craiova, Faculty of Mechanics, Department of Engineering and Management of
Technological Systems, Drobeta Turnu Severin, Romania \\ ${ }^{2}$ University of Craiova, Faculty of Horticulture, Department of Biology and Environmental \\ Engineering, Craiova, Romania \\ abucse_ionela@yahoo.com, bolimpia_ghermec@yahoo.com, c gavrilescu_elena@yahoo.com \\ dmaryana_ciobanu@yahoo.com
}

Keywords: pollution, emissions, wastewater, fuel distribution stations.

\begin{abstract}
A major source of air pollution is represented by the means of transport. The largest share of gases polluting air comes from motor vehicles, mainly due to their large number. Regardless of the type of motor, vehicles pollutes air with carbon and nitrogen oxides, unburned hydrocarbons, sulphur oxides, aldehydes, plumbum, asbestos, soot, etc. But the activity of trading fuels (diesel, gasoline), lubricants, parts, accessories and auto cosmetics (which are sold in fuel sales and distribution units) is another source of environmental contamination. From this point of view we studied some gas stations located in Drobeta Turnu Severin area, the possibility of soil pollution, waste disposal, safety zone and fire security measures. Air emissions, wastewater discharge, safety and hygiene of jobs were also studied.
\end{abstract}

\section{Introduction}

The activity of trading fuels (diesel, gasoline), lubricants, exchange parts, accessories and auto cosmetics (which are sold in fuel sales and distribution units) is an important source of environmental pollution (in air, water and soil). The pollutants characteristic for these sources are volatile organic compounds (VOCs) such as $\mathrm{C}_{4}-\mathrm{C}_{12}$ hydrocarbons (i.e., paraffins, naphthenes, and olefins [1].

In service stations, emissions originate from several sources:

- sources at ground level;

- permanent evacuations of hydrocarbons from the fuel tanks;

- the emission of hydrocarbons from the tanks is variable depending on the amount of fuel stored at a given time;

- intermittent evacuations of hydrocarbons from the fuel pump (only during refueling of motor vehicles);

- evacuations of short duration at unloading fuel tank.

In the present study, we considered three fuel distribution stations located in Drobeta Turnu Severin and Simian (in vicinity of Drobeta Turnu Severin). Station no. 1 is located in Drobeta Turnu Severin, in one of the most crowded neighborhoods of the city. Station no. 2 is situated in Drobeta Turnu Severin near the exit to Timisoara. Station no. 3 is located in the commune of Simian. The activity profile of these stations is represented by the sales of petroleum products such as fuels and lubricants, the storage of fuels and oils and the recovery of waste used oils from citizens and companies.

The three stations are supplied with fuel road tankers of 4-14 tons. The fuel is unloaded into reservoirs through the hose of the road tanker that connects to the charging holes of reservoirs. From reservoirs, fuels are delivered to consumers by pumping. The remaining petroleum products sold are packaged in plastic containers. Station operation is nonstop (8760 hours/year) [2]. 


\section{Materials and experimental procedure}

In order to characterize technological waters, samples were gathered from the following control sections:

- oil separator tank which can be found in the area of the reservoir deposit;

- general technological effluent platform.

From the oil separator tank, samples were collected from the following points:

- oil separator tank entrance (IS);

- oil separator tank exit (ES).

In order to determine the impact on air produced by the fuel distribution stations, OLDHAM apparatus (Fig. 1a) was used for determining $\mathrm{NO}_{2}$ and $\mathrm{SO}_{2}$ levels. A portable device (Fig. 1b) was used for the determination of total hydrocarbons [3].

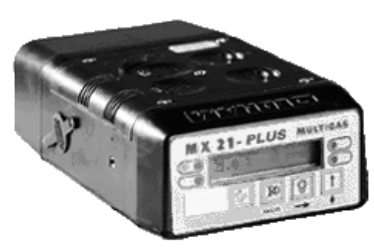

a

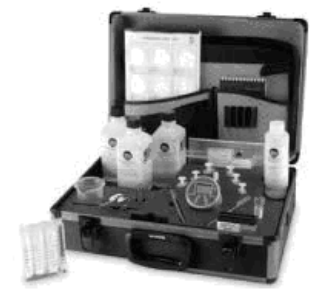

b

Fig.1 Apparatus for atmospheric pollutants

a - OLDHAM Apparatus for determination of $\mathrm{NO}_{2}$ and $\mathrm{SO}_{2}$ levels;

$\mathrm{b}$ - Apparatus for determination of total hydrocarbons

Determinations which aimed at analyzing water were performed by using DR/2010 spectrophotometer that belongs to the laboratory and whose operating principle is based on kits. With their help the following can be determined: total nitrogen, total phosphorus and CCO-Cr. Fixed residuum was determined through the gravimetric method.

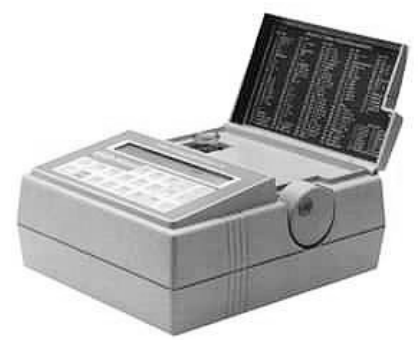

Fig.2 Portable Spectrophotometer DR/2010

\section{Results and discussions}

The city of Drobeta Turnu-Severin is situated on DN6. Stations no. 1 and no. 3 can be found on this route. The number of autovehicles that circulate in Romania has permanently grown. Road traffic has grown at $2.3 \%$ per year on average since 1990 and at $3.7 \%$ per year since 2000 . It is forecasted to grow at a similar rate to 6,800 Annual Average Daily Traffic (AADT) in 2015 [4].

Table 1 Evolution and forecast of road traffic 2000-2015 (AADT)

\begin{tabular}{|c|c|c|c|c|}
\hline & 2000 & 2005 & 2010 & 2015 \\
\hline Total & 3,709 & 4,150 & 4,957 & 5,917 \\
\hline Heavy vehicles3 & 698 & 917 & 1,110 & 1,256 \\
\hline
\end{tabular}

Source: National Company for Motorways and National Roads 
The evolution of the consumption of gasolin and diesel is shown in fig. 3 [5].

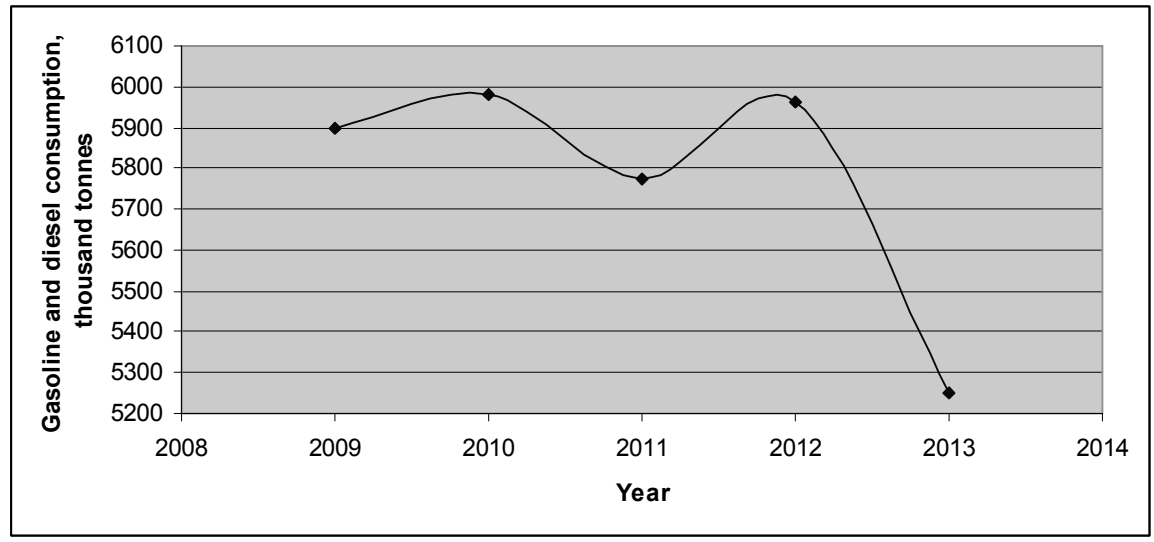

Fig.3 Gasoline and diesel consumption in Romania

According to the European Parliament and the Council Directive 94/63/EC of 20 December 1994 on the control of volatile organic compound (VOC), emissions resulting from the storage of oil and from its distribution at the terminals of the service stations, namely the VOC emissions from the system for storage and distribution of oil, represent 500,000 tons per year or $5 \%$ of the total emissions of man-made VOCs in the community; these emissions represent a significant contribution to air pollution especially in urban areas [6].

1. From the point of view of the impact on the quality of the atmosphere, the activities that represent sources of impurification are those connected to the stations of distributions of fuels and to the deposits of fuels.

The sources of impurification of the atmosphere that are specific to the station of distribution of fuels (gasoline and diesel) are:

a. the activity of filling reservoires;

b. the deposit reservoirs of fuels;

c. the supply of the reservoirs at the fuel distribution pumps.

\subsection{Station no. 1}

In the days of March $4^{\text {th }}, 5^{\text {th }}$ and $6^{\text {th }}$, measurements of air quality were made. There were determined the average concentrations per 30 minutes of total hydrocarbons, $\mathrm{SO}_{2}, \mathrm{NO}_{\mathrm{x}}$ and particulate matter (PM). The period was characterized by small speeds of the wind (below $3 \mathrm{~m} / \mathrm{s}$ ) or no wind at all. The following values were obtained:

Table 2 Characteristics of air quality for station no. 1

\begin{tabular}{|c|c|c|c|c|c|}
\hline \multirow{2}{*}{ Day } & & \multicolumn{4}{|c|}{ Pollutant } \\
\cline { 3 - 6 } & $\mathrm{HCT}$ & $\mathrm{SO}_{2}$ & $\mathrm{NO}_{\mathrm{x}}$ & $\mathrm{PM}$ \\
\hline \multirow{3}{*}{$4 / 03 / 2013$} & Min. & 951 & 0.45 & 99.27 & 11.85 \\
\cline { 2 - 6 } & Max. & 1,830 & 8.20 & 207.52 & 44.36 \\
\cline { 2 - 6 } & Average & 1,395 & 2.18 & 163.51 & 34.52 \\
\hline \multirow{3}{*}{$5 / 03 / 2013$} & Min. & 1,020 & 0.50 & 103.07 & 15.39 \\
\cline { 2 - 6 } & Max. & 2,310 & 9.34 & 218.45 & 49.47 \\
\cline { 2 - 6 } & Average & 1,395 & 2.18 & 163.51 & 34.52 \\
\hline \multirow{3}{*}{$6 / 03 / 2013$} & Min. & 1,760 & 1.36 & 199.23 & 24.16 \\
\cline { 2 - 6 } & Max. & 4,440 & 14.82 & 367.70 & 43.91 \\
\cline { 2 - 6 } & Average & 2,508 & 4.92 & 261.95 & 39.50 \\
\hline \multirow{2}{*}{ C.M.A $\mu \mathrm{Ag} / \mathrm{m}^{3}$} & 6,000 & 750 & 300 & $500 / 30$ min. \\
\cline { 3 - 6 } & & 250 & 100 & $150 / 24$ hours \\
\hline
\end{tabular}




\subsection{Station no. 2}

In the days of April $8^{\text {th }}, 9^{\text {th }}, 10^{\text {th }}$ and $11^{\text {th }}$, measurements of air quality were made. There were determined the average concentrations per 30 minutes of total hydrocarbons, $\mathrm{SO}_{2}, \mathrm{NO}_{\mathrm{x}}$ and particulate matter (PM). The period was characterized by small speeds of the wind (below $3 \mathrm{~m} / \mathrm{s}$ ) or no wind at all. The following values were obtained:

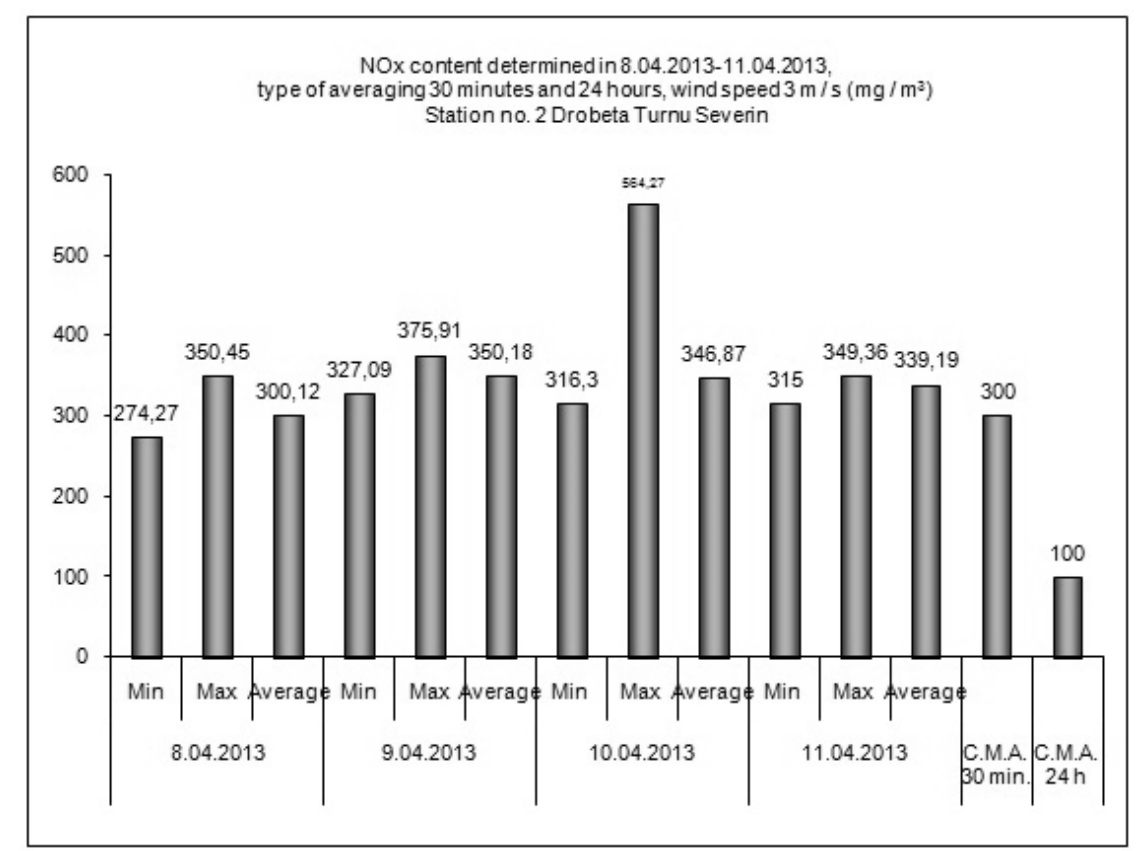

Fig.4 NOx emissions for station no.2

\subsection{Station no. 3}

In the days of April $15^{\text {th }}, 16^{\text {th }}$ an $17^{\mathrm{h}}$, measurements of air quality were made. There were determined the average concentrations per 30 minutes of total hydrocarbons, $\mathrm{SO}_{2}, \mathrm{NO}_{\mathrm{x}}$ and suspension powders. The period was characterized by small speeds of the wind (below $3 \mathrm{~m} / \mathrm{s}$ ) or no wind at all. The following values were obtained:

Table 3 Characteristics of air quality for station no. 3

\begin{tabular}{|c|l|c|c|c|c|}
\hline \multirow{2}{*}{ Day } & \multicolumn{5}{|c|}{ Pollutant } \\
\cline { 2 - 6 } & & $\mathrm{HCT}$ & $\mathrm{SO}_{2}$ & $\mathrm{NOx}$ & powders \\
\hline \multirow{3}{*}{$15 / 04 / 2013$} & Min. & 641 & 0.35 & 89.71 & 10.85 \\
\cline { 2 - 6 } & Max. & 832 & 7.2 & 199.43 & 34.36 \\
\cline { 2 - 6 } & Average & 693 & 2.1 & 152.7 & 32.58 \\
\hline \multirow{3}{*}{$16 / 04 / 2013$} & Min. & 834 & 0.52 & 101.10 & 14.12 \\
\cline { 2 - 6 } & Max. & 1,320 & 9.14 & 250.42 & 46.15 \\
\cline { 2 - 6 } & Average & 1,216 & 2.1 & 143.7 & 30.28 \\
\hline \multirow{3}{*}{ C.M.A. $\mu \mathrm{g} / \mathrm{m}^{3}$} & 1,110 & 1.16 & 175,2 & 21.18 \\
\cline { 2 - 6 } & Min. & 6,000 & 750 & 289.3 & 39.51 \\
\cline { 2 - 6 } & Max. & 2,780 & 11.9 & 300 & 36.18 \\
\cline { 2 - 6 } & Average & 2,115 & 4.12 & 234.5 & 100 \\
\hline
\end{tabular}

2. In the period of exploitation, the sources of wastewater are:

- Domestic wastewater that come from the social administrative group and which are collection through a sewerage network, directed towards a septic tank and evacuated in the sewerage of the city. 
- Rainfall waters that were unpurified by accident when the platform of the pumps was washed.

From the balance of water of a fuel distribution station, the sources of technological wastewater result, as shown in fig. 5:

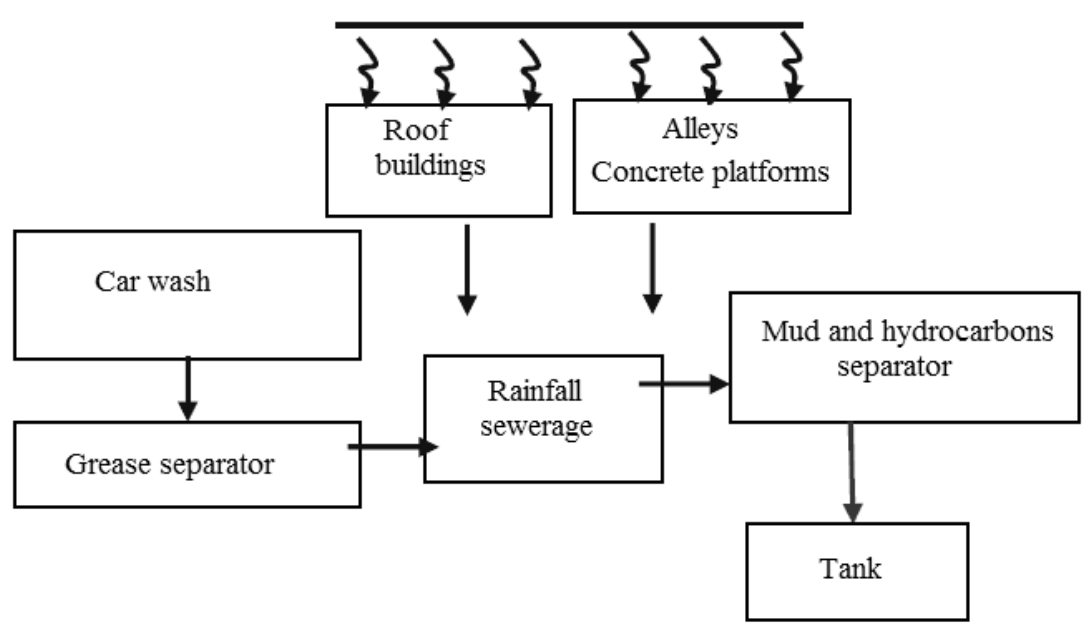

Fig.5 Technological wastewater sources and treatment

Large quantities of water are used in the activities of distributing fuel stations especially in car wash operations. Technological wastewater result from car wash operations and also when the concrete platform or the platform of pumps is washed [7]. The wash is realized either with water from the alimentation network of the deposit or due to the rain. The pollutants that are present in technological waters are mainly represented by suspension materials, oil products and organic substances.

Samples for grease separator were collected in different periods, respectively:

- Collection I-R ${ }_{1}$ - in March 2013;

- Collection II-R 2 - in April 2013.

The results of the analyses made on the collected samples are presented in table 4 .

Table 4 The results of the analyses on collected samples for grease separator

\begin{tabular}{|l|c|c|c|c|c|}
\hline \multirow{2}{*}{ Quality indicators } & \multirow{2}{*}{ Unit } & \multicolumn{2}{c|}{$\mathrm{R}_{1}$ (March 2013$)$} & \multicolumn{2}{c|}{$\mathrm{R}_{2}$ (April 2013) } \\
\cline { 3 - 6 } & & $\mathrm{IS}$ & $\mathrm{ES}$ & $\mathrm{IS}$ & $\mathrm{ES}$ \\
\hline $\mathrm{pH}$ & & 6.5 & 6.5 & 7.0 & 6.5 \\
\hline Total suspensions & $\mathrm{mg} / \mathrm{dm}^{3}$ & 13,674 & 299.2 & $1,054.4$ & 66.4 \\
\hline Volatile suspensions & $\mathrm{mg} / \mathrm{dm}^{3}$ & 12,926 & 120 & 574,4 & 28,8 \\
\hline $\mathrm{CCO}-\mathrm{Cr}$ & $\mathrm{mg} / \mathrm{dm}^{3}$ & 10,864 & 494.7 & 1,666 & 137.2 \\
\hline $\mathrm{CBO}_{5}$ & $\mathrm{mg} / \mathrm{dm}^{3}$ & - & 189.3 & 326 & 99.9 \\
\hline Substances extractable by oil ether & $\mathrm{mg} / \mathrm{dm}^{3}$ & $5,686.3$ & 267.2 & 357.2 & 67.6 \\
\hline
\end{tabular}

The quality of general effluent from the fuel distribution stations is shown in table 5. 
Table 5 The quality of general effluent from the fuel distribution stations

\begin{tabular}{|l|l|c|c|}
\hline \multicolumn{1}{|c|}{ Quality indicators } & Unit & Value & $\begin{array}{c}\text { Limite value } \\
\text { C90-83 Normative }\end{array}$ \\
\hline $\mathrm{pH}$ & & 6.5 & $6.5-8.5$ \\
\hline Total suspended solids $\left(105^{\circ} \mathrm{C}\right)$ & $\mathrm{mg} / \mathrm{dm}^{3}$ & 43.2 & max. 300 \\
\hline Volatile suspended solids & $\mathrm{mg} / \mathrm{dm}^{3}$ & 29.8 & - \\
\hline CCO-Cr & $\mathrm{mg} / \mathrm{dm}^{3}$ & 117.6 & max. 500 \\
\hline CBOs & $\mathrm{mg} / \mathrm{dm}^{3}$ & 10.7 & max. 300 \\
\hline Detergents in technological water & $\mathrm{mg} / \mathrm{dm}^{3}$ & 0.12 & - \\
\hline Substances extractable by oil ether & $\mathrm{mg} / \mathrm{dm}^{3}$ & 60 & max. 30 \\
\hline
\end{tabular}

The limit value is in accordance to C90-83 - Regulatory for the unloading of wastewaters in the sewerage networks of populated stations.

\section{Conclusions}

Collected wastewater that has a high content of petroleum products requires an adequate pretreatment to assure the quality requirements. In air, the concentrations of total hydrocarbons and NOx exceed the maximum allowable concentration both for 30 minutes and for 24 hours.

Based upon the results obtained in the study, the following conclusions can be drawn:

In what regards the environmental factor WATER:

At no. 1 and 2 stations, the collected wastewaters on the rainfall-technological circuit are evacuated in the sewerage of Drobeta Turnu-Severin with a high amount of oil products and requiring a pre-purification in order for them to be evacuated in conditions of quality imposed by the regulatory in force. These can have a negative impact on the sewerage network, respectively on the purification station.

Domestic wastewater resulted are collected and evacuated accordingly with no negative impact on the surface waters from the area.

At station no. 3 from Simian, the rainfall waters collection from the technological platforms (the area of the distribution pumps) from all the distribution stations, are evacuated in the local system of rainfall waters. In order to ensure the protection of the quality of surface and underground waters from the area, it is considered to be necessary the existence of a separator of oil products.

At this station, wastewaters are managed accordingly, without generating a negative impact on the surface waters from the area.

In what regards the environmental factor AIR:

At stations no. 1 and 2 from Drobeta Turnu Severin, the concentrations of total hydrocarbons and NOx exceed the admitted CMA both at 30 min and at 24 hours. The parameters $\mathrm{SO}_{2}$ and material powders do not exceed the maximum limits.

\section{References}

[1] Zheng J. et al., Characterization of gas station emissions during the CAREBeijing 2008 field study, Atmos. Chem. Phys. Discuss., 11, 14719-14746, 2011, www.atmos-chem-physdiscuss.net/11/14719/2011/

[2] http://www.arb.ca.gov/ab2588/rrap-iwra/gasiwra.pdf, David Craft, Sara Demyanovich et.al, Gasoline Service Station Industrywide Risk Assessment Guidelines.

[3] Gavrilescu, E., The study of air quality indices in Craiova municipality, Museum of Oltenia Craiova. Oltenia. Studies and communications. Nature Sciences. Tom. 27, No. 1/2011 ISSN 14546914 (In Romanian). 
[4] Government of Romania, Ministry of Transport, Sectoral Operational Programme Transport $2007-2013$.

http://www.fonduriue.ro/res/filepicker_users/cd25a597fd62/Doc_prog/prog_op/5_POST/POST_ver siunea aprilie 2013.pdf

[5] National Institute of Statistics.

[6] European Parliament and Council Directive 94/63/EC of 20 December 1994 on the control of volatile organic compound (VOC) emissions resulting from the storage of petrol and its distribution from terminals to service stations.

[7]http://apmdb.anpm.ro/upload/27985_raport\%20la\%20studiul\%20de\%20evaluare\%20Romstar.pd f Rapport on the study of impact on the environment, construction of the station of distribution of fuels, car wash and GPL station 